\title{
Condição Juvenil na América Latina: demandas e enfrentamentos às iniquidades em saúde
}

Desde a primeira década dos anos 2000 a condição juvenil vem sendo refletida em inúmeros diagnósticos e pesquisas na América Latina ${ }^{1}$, buscando ampliar o entendimento da situação social da juventude e subsidiar políticas públicas com foco no grupo dos 15 aos 29 anos, no caso brasileiro. Um dos pressupostos afirma que a juventude não pode ser compreendida como uma fase transitória para a vida adulta e que as expectativas de autonomia, emancipação e inserção na vida social desse segmento populacional são diferenciadas em função das desigualdades estruturais locais e regionais².

Isto significa dizer que as formas de existir, (re)produzir a vida e obter acesso e oportunidades dos jovens são heterogêneas e balizadas pelo cenário social e territorial no qual se inserem, caracterizado por condições materiais, relações de gênero, padrões sexuais e pertencimentos étnico-raciais. Assim, temas referentes à saúde, à educação, ao mundo do trabalho, à cultura, à segurança pública, à diversidade sexual e à participação social e política, problematizam as representações correntes sobre o significado de ser jovem na contemporaneidade, considerando as especificidades dos contextos em que se desenvolvem as distintas trajetórias juvenis.

Por meio deste número temático objetivamos estimular o debate sobre aspectos que abordam a relação entre condição juvenil contemporânea e saúde nos países latino-americanos. Tal iniciativa resulta dos esforços da Agenda Jovem Fiocruz, uma plataforma colaborativa da Fiocruz, na produção de insumos conceituais e metodológicos para formulação de políticas dirigidas à juventude com enfoque na saúde. As questões trazidas pelos 25 artigos mapeiam preocupações correntes, como: análises epidemiológicas e socioantropológicas sobre agravos em saúde que acometem os jovens; violências; avaliações de serviços de atenção à população juvenil e estudos sobre fenômenos contemporâneos, como os efeitos do uso de tecnologias de informação e comunicação.

O conjunto dos trabalhos reunidos ilustra a contribuição e o potencial do campo da saúde para as políticas públicas voltadas à juventude e faz um convite ao diálogo intersetorial e multidisciplinar. Assim, visa ampliar as abordagens históricas sobre a adolescência nas pesquisas em saúde, com enfoque nos fatores de risco e/ou proteção dos comportamentos, na educação para a saúde e situações de vulnerabilidade. Salientamos que, embora a adolescência seja parte da condição juvenil, ela não esgota o potencial heurístico de análises que alcançam as faixas etárias mais elevadas. Cabe, portanto, atentar para temas que interpelam fortemente a saúde da juventude, como as múltiplas expressões de violências, a saúde de jovens que ocupam trabalhos informais e precarizados, a interseccionalidade de gênero, raça e classe, assim como os ativismos juvenis contemporâneos para além da noção reificada de protagonismo juvenil.

Por fim, esse número temático foi produzido em meio à pandemia de COVID-19 que descortinou uma situação de dramática vulnerabilidade para uma parcela significativa de jovens. A necessidade de sobrevivência, os desafios para a educação de jovens e o aumento da pobreza e da fome, ilustram como o campo da saúde pode dizer muito mais a respeito da condição juvenil contemporânea.

André Sobrinho (https://orcid.org/0000-0002-9986-1833) ${ }^{1}$

Edinilsa Ramos de Souza (https://orcid.org/0000-0003-0903-4525) ${ }^{2}$

Kathie Njaine (https://orcid.org/0000-0003-3250-2331) ${ }^{2}$

Marcos Nascimento (https://orcid.org/0000-0002-3363-4232) ${ }^{3}$

Simone Souza Monteiro (https://orcid.org/0000-0003-2009-1790) 4

${ }^{1}$ Fundação Oswaldo Cruz (Fiocruz). Rio de Janeiro RJ Brasil.

${ }^{2}$ Escola Nacional de Saúde Pública Sérgio Arouca, Fiocruz. Rio de Janeiro RJ Brasil.

${ }^{3}$ Instituto Fernandes Figueira, Fiocruz. Rio de Janeiro RJ Brasil.

${ }^{4}$ Instituto Oswaldo Cruz, Fiocruz. Rio de Janeiro RJ Brasil.

\section{Agradecimentos}

Ao apoio financeiro da Presidência da Fiocruz e à colaboração de Sofia B. Souza.

\section{Referências}

1. Takeiti B, Gonçalves M, Oliveira S, Elisiario T. O estado da arte sobre as juventudes, as vulnerabilidades e as violências: o que as pesquisas informam? Saude Soc 2020; 3:e181118.

2. Alvarado S, Vommaro P, organizadores. Jóvenes, cultura y política en América Latina: algunos trayectos de sus relaciones, experiencias y lecturas. Argentina: Ediciones Homo Sapiens; 2010. 